\title{
The Role of Private Water Vending in Nigeian Peri-Urban Informal Settlements: Implication for Policy Makers
}

\author{
Hassan Tsenbeya Ishaku ${ }^{1}$, Ajayi Abayomi Peters', Ali Haruna², Fabian Mazawuje Dama² \\ ${ }^{1}$ Department of Urban and Regional Planning, Universiti Teknologi Malaysia, Johor, Malaysia \\ ${ }^{2}$ Department of Urban and Regional Planning, Federal University of Technology, Yola, Nigeria \\ E-mail: tsenbeya@yahoo.com, abayomipeters@yahoo.co.uk, harunaali59@yahoo.com,fabiandamam@yahoo.com
}

Received September 2, 2010; revised October 10, 2010; accepted November 16, 2010

\begin{abstract}
This paper presents a study of water vending in 3 informal settlements of Yola North in Adamawa State of Nigeria. These settlements represent the fast growing urban areas often dwelling in unplanned and unsecured tenure. Access to safe water supply has great influence on the health, economic productivity and quality of life of the people. But meeting this need is one of the major challenges facing the urban communities of Nigeria today. A field survey was conducted in the area with 100 observations of households in each of the three informal settlements. These settlements are Sabongari - University village, Vinikilang and Wuro Jabbe. The survey solicited for response concerning household water source, water per capita use and household size. Findings revealed that about 92\% of respondent in Sabongari-University village, 66\% in Vinikilang and 87\% in Wuro Jabbe depend on vended water from borehole, hand dug well as well as surface water sources which are delivered by hand pushed trucks. Owing to the absence of piped water networks in the study area, households are forced to rely on available water sources which are precursor to water borne diseases. It is advocated that the public agencies should evolve special programs for regularizing informal settlements, meaning the legalization of land tenure, layout corrections and service upgrading if service is to meet the poor informal dwellers.
\end{abstract}

Keywords: Implication for Policy Makers, Private Water Vending, Peri-Urban Informal Settlements

\section{Introduction}

The World Health Organization and United Nations Children Emergency Fund WHO/UNICEF [1] reported that water vending is usually undertaken by formal bodies, such as water utilities themselves or registered associations, or by small-scale informal suppliers. Where formal vending in water supply is practiced, the majority of the water is likely to be supplied in tankers and will supply a service to the end user equivalent to in-house water supply. Typically, such water will come either from treated utility supplies or from registered sources. Informal suppliers will tend to use a range of sourcesprotected or unprotected-and deliver small volumes for domestic use, often in containers carried by hand-push trucks or animals over a long distance. Formal systems will be much easier to control and regulated than informal systems.

Due to the unregulated nature of the informal water vendors most of the water sold to the public are not of potable quality a situation that spurs up water borne related diseases. Since households have no other alternative sources because of their nature of jobs as hawkers, artisans and laborers these informal settlements is the only place that can afford them cheap accommodation, food and recreation of a sort as against the relatively higher living standards in the core centers of the urban areas.

Hutin et al. [2] stated that vended water is common in many parts of the world where scarcity of supplies or lack of infrastructure limits access to suitable quantities of drinking-water. Though water vending is more common and involves a greater diversity of distribution in developing countries. Vended water can provide a needed resource in areas that are poorly served by traditional services, but both the quality and quantity of supplies can vary. Vended water has been associated with outbreaks of diarrhea disease as some of the vended water is obtained directly from unprotected source such as unprotected wells and surface water such as rivers/ 
streams, ponds and canals etc. WHO [3].

In formal housing is a common phenomenon in most urban centers of Nigeria. It is a response to decongest the central business district (CBD) and to allow for new planned buildings to meet contemporary needs. The CBD is the section of the city that is overcrowded with large number of population lacking in accessibility and other facilities living conditions is detrimental to health and social well being. The recent growth of urban areas has shown that urban centers occupies an extensive area which planners, researchers and scholars are willing to further explore.

A high proportion of the residents of in formal residential areas which constitute the bulk of housing units do not possess legal title to their plots this constitutes an important constraints to service provision. As service provision amounts to de facto recognition of property rights, it is a step which the technical agencies responseble for infrastructure service provision are neither willing nor authorized to take. This means that there is no place for informal settlements in terms of physical planning and the provision of facilities, utilities and services. Many informal urban dwellers, excluded from the provision or unhappy with the service, have long resorted to other means of supply: free sources (wells, rivers streams, ponds, rain water etc.) (see Figure 1 and Figure 2) and hence the emergence of many operators in local water markets involved in production of water through private boreholes, transport by tanker trucks or distribution by local reselling, home delivery, street vending etc.

Sylvy [4] stated that the ongoing redefinition of the role of the state is as much as a response to failings in bureaucratic regulation and public decision-making process as the pragmatic outcome of the failures of central planning and the mixed economy, amplified by increasing macro-economic constraints and diminishing sources of public sectors financing. In increasingly informal contexts reforms can only be applied in a fragmented and incomplete manner.

In fact, in areas of recent urban expansion where tenure status is often precarious and illegal, as well as in the poorest neighborhoods, official services are not in a position to meet urban demand in full. These activities, which are tolerated completely takes over the public water provision especially in the so called informal settlements. However, this informal water economy, which is both cause and consequence of weak managerial capacity of the public authorities, limits the scope of reform and places various obstacles on its ways.

\subsection{Past Studies on Water Vending}

Whittington et al. [5] in the study of water vending and

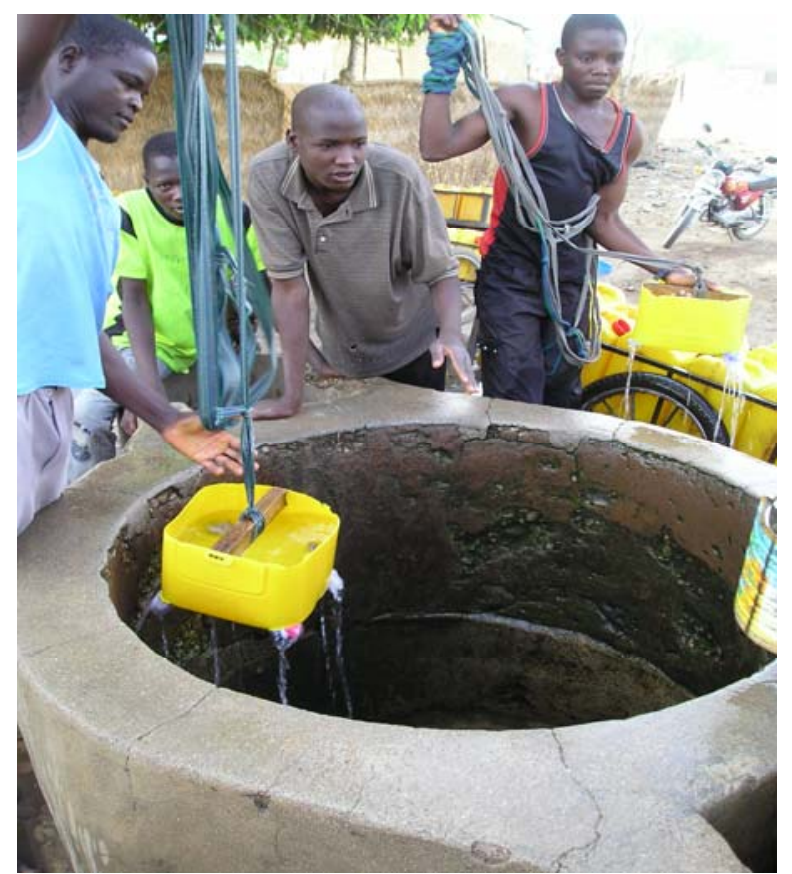

Figure 1. Water vendors fetching water from unprotected hand dug well.

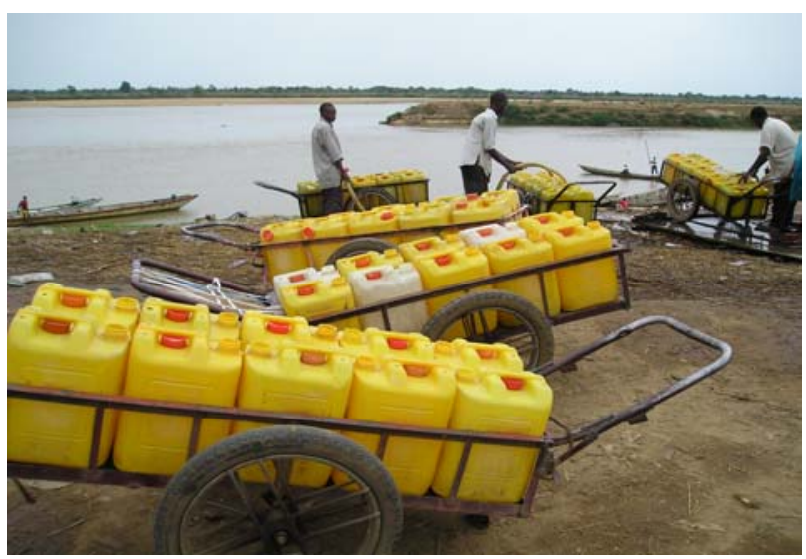

Figure 2. Water vendors trotting water from a river using water pumps.

willingness to pay for water in Onitsha, Nigeria, stated that the water vending activities can yield valuable information for water supply planning and unexpected policy insight. The vast majority of Onitsha obtains its water supply from an elaborate and well-organized water vending system which has been created and is operated by the private sector. Many of the households who purchase water from tanker trucks resell the water by bucket to individuals who cannot afford large storage tanks or who cannot be reached by the tanker trucks. They further stated that even during rainy season, the revenues from water vendor sales were still several times higher than water utility. On annual basis, households in 
Onitsha are already paying water vendors over twice the cost of piped water. Their study illustrates a rapid reconnaissance survey of water vending activities and willingness of households to pay for improved services. It is unfortunate that, as the study reveals, households still pay the water vendors as much as twice the cost of piped water during the rainy season when they can actually harvest water from rooftops or hand-dug wells which they have full control of ownership at their doorsteps.

Roohi [6] in the study of water vending in Karachi, Pakistan stated that private water vending industry is an important source of service delivery in most developing countries of the world. It serves as a supplemental service to households with private water connections, due to limited service from the public utility. It is the major source of water supply mostly undertaken by the informal sector. This study evaluates the extent to which water vending affects households' water supply situation and generates excessive profit for vendors. This study argued that where water vending co-exists with piped supply network, it posses a challenge to policy makers in water supply planning. Findings revealed that water vending market may not be economically efficient. Although the vending market provided only $9 \%$ of water consumed by city residents on daily basis, it earns more than $50 \%$ of all revenue received from water. Existing government policies fails to address the consequences of unregulated exploitation of ground water by private individuals. In view of the finding this study advocated for a regulatory reforms.

Adekalu et al. [7] in a study of four cities in southwest Nigeria, concluded that owing to deficiencies in piped water availability, households invest in coping strategies in the form of alternative supplies and storage facilities to supplement piped water. This coping strategy has important implications for the consumers. The choice of any particular system for a given usage depends on the perceived attributes of the system. Households will have to decide which of the sources to use for a particular purpose and this decision is often complex. The choice of any source for a particular use will depend on whether it meets the demand of the people both in terms of quantity and quality based on certain attributes such as clarity odors and taste, reliability/availability and distance from the households.

Nkwocha [8] recently examined the water supply deficiency and its general impact on rural development within the Niger delta region and stated that there was a growing concern about the marginalization of the region in terms of infrastructure and social services provisions. Results showed that the weekly mean household water demand for the area was 1,108 liter per household (lph) as against the actual household water consumption of only $355 \mathrm{lph}$. As such, the people living in the area experienced acute water deficiency which had impacted negatively on their social, economic and political lives despite the fact that the region has abundant water resources, more than any part of Nigeria.

The above scenarios point to the facts that public water supply systems in Nigeria are characterized by insufficient supplies and chronic deficits. The private water supply meanwhile has remained financially solvent and fostered a rapid growth in capacity through informal sector but characterized by high cost because of the private sector's perceived profit motives. The studies by Whittington et al. and Adekalu represent the urban water supply situation while the study by Nkwocha centered on the rural environment which have both economic and social implications for the consumers. Their studies revealed that the rural areas have benefited relatively little from water supply intervention compared to their urban counterparts. The reason why the rural communities are often ignored is because of their perceived low income level as peasant farmers who can not afford the prices of such improved water facilities.

\section{Method of Data Collection}

Jimeta lies between latitude $9^{\circ} \mathrm{N} 4^{\circ} \mathrm{N}$ of the equator and longitude $12^{\circ} \mathrm{E} 38^{\circ} \mathrm{E}$ of the Greenwich meridian and is situated on an altitude of about $185.9 \mathrm{~m}$ above sea level. Jimeta falls within the north Guinea Savannah region. Jimeta is the administrative headquarters of Adamawa State while Yola is the traditional seat of the Lamido.of Adamawa State. It should be noted that Jimeta and Yola are separate towns, the former being the administrative headquarters of Adamawa State while the later is the traditional seat of the Lamido of Adamawa meaning the emir and the chairman of Adamawa state emirate council with its headquarters in YOLA town. (Gateway to land and water information) [9].

These informal settlements were selected based on their spatial location and nature of haphazard development experienced in these settlements in recent times. Unlike many slums dwelling which are situated within the city's central business district (CBD) and characterized by dense population, these settlements are located at the urban periphery due to urban growth in recent time? The stratified sampling of households was adopted for this study. A total of 300 households were surveyed with 100 observations from each settlement. These settlements include (1) University village (2) Vinikilang and (3) Wuro-Jabbe. In each settlement, every 3rd household in a street was selected for inclusion in the survey. Four variables were to obtain the needed infor- 
mation that will justify why majority of household rely mostly on vended water for their domestic purposes.

\section{Results and Discussion}

The variables used in this study include the following: Sources of water supply, water per capita use, water demand and household size. The various sources of water supply were identified and classified into three (3) types namely: surface water (rivers, ponds and perennial streams), Drilled tubes such as boreholes and well, and rainwater collection. Unlike the university village and WuroJabbe which are located at the extreme end of Jimeta and rely solely on water vending most of the times, the settlement of Vinikilang is located within the Benue valley where households take advantage of the river to supplement their water demand. Residents of University village sometimes take advantage of the University water supply system as pipes can be seen outside the university fence. This is part of community service rendered by the university.

Figure 3 reveals that the water per capita use in the study area is not evenly distributed, however, 58\% of household in the University village uses between 30-40 liters of water daily while in Vinikilang $60 \%$ of the households uses between 30-40 liters of water daily possibly because of the river Benue However the situation is different in the case of WuroJabbe where the water per capita use accounts for only 34\% due to limited numbers of boreholes (2) in the settlements as compared to University village which have 11 borehole operators and 7 in Vinikilang.

The average household size of 5 persons was used to arrive at the water demand for these settlements based on the national average water use of 63 liters per person per day in Nigerian urban centers. The average total per capita water demand in liters per day stood at 58, 60, and 34 for University village, Vinikilang and WuroJabbe respectively. These values (average of 50\%) for the study area slightly below the national average water demand for Nigeria urban centers of 63 liters per capita per day.

Figure 4 shows that water vending account for the bulk of water sources in the three settlements. The break down shows that University village accounts for $79 \%$, Vinikilang $62 \%$ and Wuro-Jabbe $71 \%$ respectively. The overall average stood at $71 \%$ for the surveyed settlements

Figure 5 indicates that respondents within the household size of 1-5 account for $67 \%$ while those above 15 stood at 3\%. This was used in calculating the water demand of residents in the study area. It should be noted that population and the activity pattern prevailing is a function of water per capita use.
Figure 6 below shows the monthly income of respondents. More than half of the respondents (51\%) earn less than N10, 000 monthly. This figure is slightly above the minimum wage prescribed by the government for civil servants in the state of N7, 500.00. This reveals that most of the informal residents are low income earners due to the nature of work as hawkers and artisans. However, the situation is slightly different in WuroJabbe where $37 \%$ of respondent earn more than the government prescribed minimum wage. It becomes apparent from the foregoing that residents of these settlements are low and middle income working class who can not afford the high rents in the city hence their choice for the informal settlements.

\section{Implication of the Results for Policy Makers}

The unregulated and over extraction of ground water from the aquifers results in reduction of ground water resource and lowering the water table level. This situation calls a rethink in the policy on water resource management catalyzed by government interventions, external agencies and non-governmental organizations NGOs under the supervision and control of local elected bodies.

Vended water has been associated with outbreak of diarrhea diseases as some of the vended water are obtained directly from unprotected sources such as wells and surface water such as rivers, streams, ponds and canals. The New Nigerian newspaper [10] reported that cholera out break have been recorded in northern Nigeria claiming over 80 lives ...

"Recently, reports of outbreaks of the deadly cholera disease in parts of the northern Nigerian states with alarming toll must have disturbed all well-meaning citizens, especially given the fact that even as it spread fast, the disease is preventable with the simple observance of hygiene by the populace in the country. Over 80 persons died of the disease in the latest bouts including the most recent one in Yobe State. In Adamawa State alone, it claimed the lives of 27 people, with about 120 families affected in Demsa Local Government area. There were similar reports of the disease from Kano, Kogi, Kaduna and Bauchi states which altogether point at the possibility of further spread if urgent preventive and curative measures are not taken all over."

Similarly the outbreak of cholera in many parts of the northern Nigeria of recent 2010 in Adamawa, Bauchi, Kaduna, Kogi and Yobe states as reported by the New Nigerian Newspaper of 12/09/09 attest to the fact that self water supplies exposes residents to disease attacks. Despite the substantial efforts to improve the quality and 


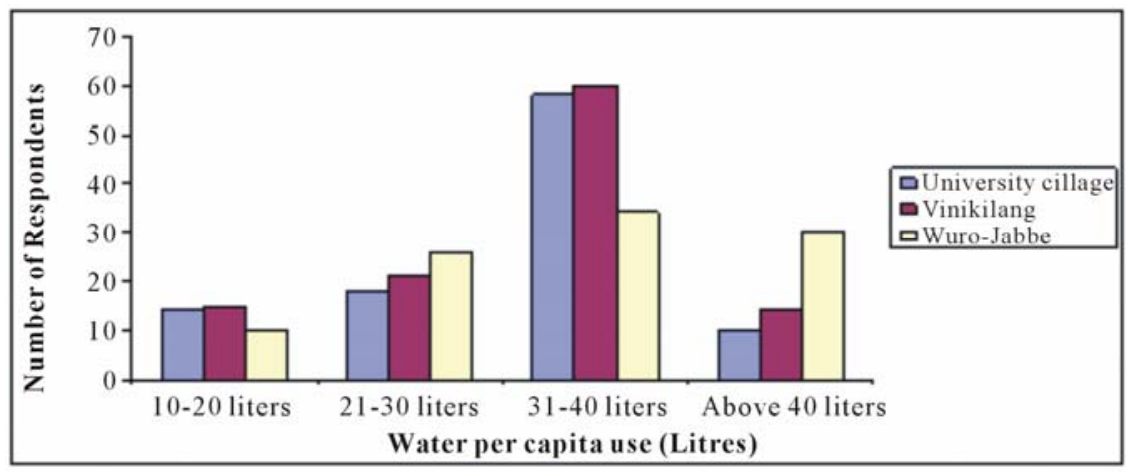

Figure 3. Water per capita use of respondents.

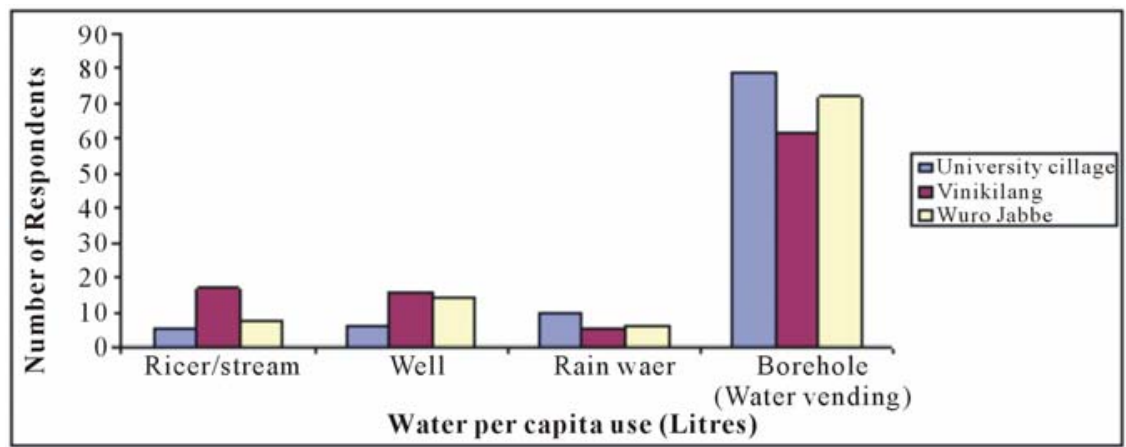

Figure 4. Water source.

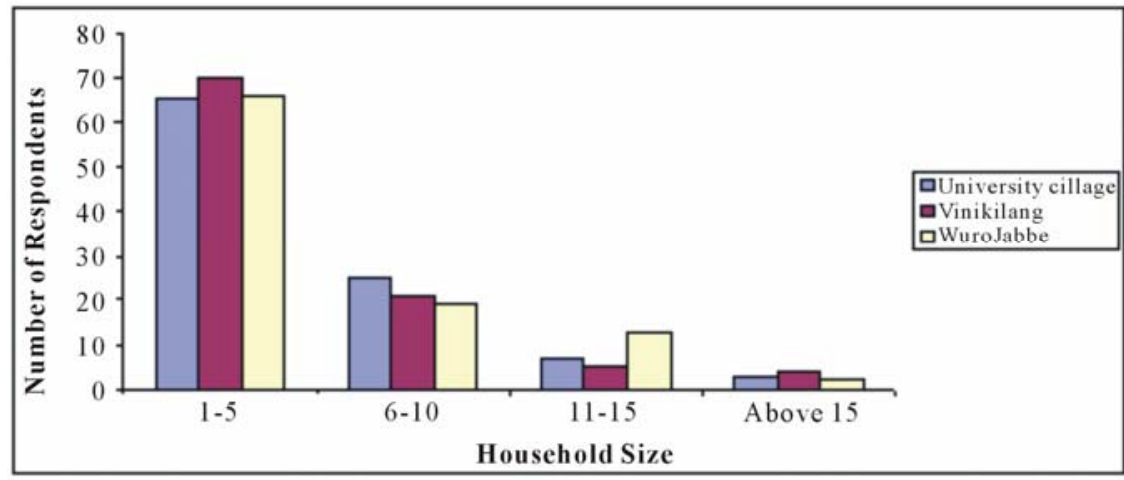

Figure 5. Household size of respondents.

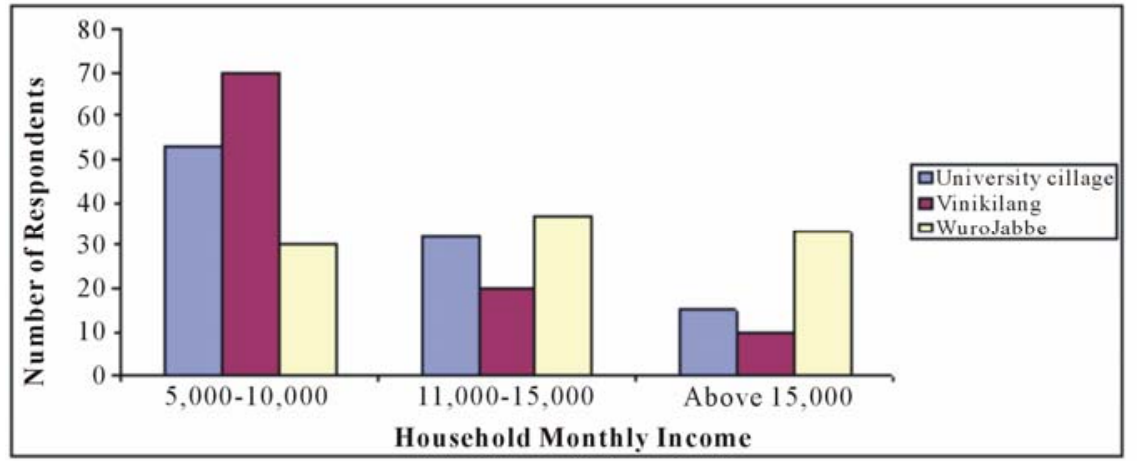

Figure 6. Respondent's monthly income. 
coverage of service; one quarter of the urban population and more than half of the rural populations do not have access to improved public water system. In the light of the above, however, private sector participation in water supply service was advocated as a way out of the water crisis. Again the rural communities did not featured in this urban thinking as all efforts was centered on the urban environment as it was misconceived that the rural poor can not afford the high rates of water services charged by the private sectors because of their perceived profit motives.

The existing government policies fail to address the consequences of unregulated extraction of underground water by private individuals. The urban development planners and the policy makers understands that residents of informal settlements have the right to full access to service delivery but are unable to make provisions for these settlements to be incorporated into the planning schemes of the urban centers. The implication is that this bias will continue unless they recognize the need to legalize the property rights of resident of informal settlements. Above all these settlements should be reassessed with the aim of making a development plan to guide physical development in an orderly manner.

A high proportion of the residents of informal residential areas which constitute the bulk of housing units do not possess legal title to their plots this constitutes an important constraints to service provision. As service provision amounts to de facto recognition of property rights, it is a step which the technical agencies responsible for infrastructure service provision are neither willing nor authorized to take.

\section{Conclusions}

Independent surveillance is an important element of ensuring that vended water is safe. One of the obstacles to effective monitoring can be lack of records and documentation identifying water vendors. Therefore implementation of registration systems should be considered.

Since service delivery amounts to defacto recognition of property rights, residents of informal settlements are forced to rely on free water source which is precursor to water borne diseases. This is because of their low income level as hawkers, artisans and laborers. The recognition of informal settlement as part of the planning scheme and the democratization of legal titles to plots by development planners and policy makers in such areas will be a positive step in the right direction.

\section{References}

[1] WHO/UNICEF (2000) "Global Water Supply and Sanitation Assessment Report,” Geneva, World Health Organization, Water Supply and Sanitation Collaborative Council and United Nations Children Fund, Joint Monitoring Program for Water Supply and Sanitation.

[2] Y. Hutin, S. Luby and C. Paquet, "A Large Cholera Outbreak in Kano City, Nigeria: The Importance of Hand Washing with Soap and Dangers of Street-Vended Water,” Journal of Water and Health, Vol. 1, No. 1, 2003 pp. 45-52.

[3] WHO (2006) "Progress on Drinking Water and Sanitation, a 2008 Millennium Development Goal MDG Assessment on progress for Children: A Report Card.” www.childinfo.org/water.html

[4] J. Sylvy, "The Right of Water versus Cost Recovery: Participation, Urban Water Supply and the Poor in Sub-Saharan Africa," Environment and Urbanization, 2002.

http://eau.sagepub.com/cgi/content/abstract/14/1/231

[5] D. Whittington, D. T. Lauria and X. M. Mu, "Paying for Urban Services: A Case Study of Water Vending and Willingness to Pay for Water in Notice, Nigeria,” Full text via cross Referenced View Record in Scopus, 1989.

[6] A. Roohi, "The Role of Private Vending in Developing Water Services Delivery: The Case of Karachi, Pakistan,” World Bank, 1999.

http://papers.ssrn.com/so13/papers.cfm?abstract_id=8734 13

[7] K. O. Adekalu, J. A. Osunbitan and O. E. Ojo, "Water Sources and Demand in South Western Nigeria: Implications for Water Development Planners and Scientists," 2002. http://www.science direct.com/science

[8] E. E. Nkwocha, "Water Supply Deficiency and Implications in the Niger Delta Region of Nigeria," 2008. http://www.springerlink.com/content/1bn488q22074k234 /fulltext.pdf

[9] Gateway to Land and Water Information: Nigeria National Information. http://www.gateway to land and water

[10] New Nigeria Newspaper, "Lack of Safe Drinking Water," 2009. http://www.newnigeriannews.com/-cached-similar 